A Narrative Review of Asian Female Travellers: Looking Into the Future Through The Past

Elaine Chiao Ling YANG $^{\mathrm{a}, *}$, Catheryn KHOO-LATTIMORE ${ }^{\mathrm{a}}$, and Charles ARCODIA ${ }^{\mathrm{a}}$

${ }^{a}$ Griffith Business School

Department of Tourism, Sport and Hotel Management

Nathan Campus, Griffith University

170 Kessels Road, Nathan

Brisbane, Queensland 4111, Australia

Acknowledgement: The Version of Record of this manuscript has been published and is available in Current Issues in Tourism since 19 July 2016.

URL: http://www.tandfonline.com/eprint/txFEHUpIT9VsuDeC34rH/full

DOI: $10.1080 / 13683500.2016 .1208741$ 


\section{A narrative review of Asian female travellers: Looking into the future through the past}

Following the rise of tourism in Asia, a growing female travel market has been observed in the region. Nevertheless, limited research has considered the travel experience of Asian women. In response to the dearth of research on Asian female travellers, this study employs a narrative synthesis approach through a postcolonial feminist lens to review the extant literature on Asian female travellers, with the aim to contribute to a cultural understanding of the historical and contemporary travel practices of Asian women. Based on this review, it is evident that Asian women's travel behaviour is influenced by cultural identities and gender stereotypes. However, existing literature has also demonstrated the agency of Asian women in resisting discriminatory gender practices in tourism, which is represented in the transformation of the identity of Asian female travellers. Accordingly, an agenda for future research is proposed and some implications for the industry are discussed. This study addresses the western-centric and androcentric criticisms in tourism field and provides an alternative reading of women's travel behaviour from an Asian perspective. This study has contributed to the critical tourism scholarship in Asia and has built an important foundation for future research on Asian female travellers, an area that is not well investigated.

Keywords: Asian; cultural value; female traveller; gender norms; narrative synthesis; postcolonial feminism 


\section{Introduction}

Before the mid-twentieth century, leisure travel was a privilege for men and just a few women from the upper class (Harris \& Wilson, 2007). Women travelling independently were considered inappropriate by society (Craik, 1997) and arguably, this perception has endured until today in some parts of the world where gender inequality persists. Massive social transformations took place after the Second World War, and these have resulted in changing social circumstances and structural conditions for women. With the rise of global capitalism and the improved access to education, employment, and financial independence, the contemporary female travel market began to emerge in the West in the 1970s (Frohlick, 2013) and has expanded steadily since then (Bond, 2015). A similar growth was observed in Asia; female travellers had become noticeable in Japan in the 1980s (Cai \& Combrink, 2000), China in the 1990s (Li, Wen, \& Leung, 2011), and Asia in general at the turn of the twentyfirst century (Amadeus, 2013; Andrews, 2015). Landmark studies and recent statistics show that women represent half of the contemporary travel market (Bond, 2015; Harris \& Wilson, 2007), and dominate the adventure travel, solo holiday, and backpacking markets (Kim, 2014; Wilson \& Harris, 2006; Wilson \& Little, 2005). It is projected that women's participation in tourism will continue to grow, and this growth will be especially remarkable in the AsiaPacific region, with an estimation of a 400\% increment by 2030 (eGlobal Travel Media, 2014).

In response to the rise of female travellers, an increasing amount of research has studied women's travel experience over the last two decades. For instance, a number of edited books (Apostolopoulos, Sönmez, \& Timothy, 2001; Pritchard, Morgan, Ateljevic, \& Harris, 2007; Swain \& Momsen, 2002) and journal special issues (Bowen, 2005, 2008; Swain, 1995) have been dedicated to gender studies in tourism. Nevertheless, existing literature is predominantly based on western women's experiences and little is known about Asian female travellers. As of April 2015, in relation to Gursoy and Sandstrom's most recent list (2014) of the top 10 tourism journals, fewer than 10 articles have considered Asian women's travel experience. It indicates an apparent dearth of research on this rising market.

Within the limited research on Asian female travellers, travel behaviour appears to be a popular research topic, including travel motivation (Li et al., 2011), tourist gaze (Asbollah, Lade, \& Michael, 2013; Zhang \& Hitchcock, 2014), and gender difference in behavioural 
patterns (Huang, 2006; Kim, Lee, \& Chung, 2013). Most importantly, scholars have reported the influence of Asian gender norms and cultural identities on female travel behaviour (Asbollah et al., 2013; Teo \& Leong, 2006; Zhang \& Hitchcock, 2014). As documented in prior literature, Asian women are regarded by the Asian societies and at times, by themselves, as more vulnerable and dependent compared to western women (Teo \& Leong, 2006; Yang, 2016) and thus, they are seen as less inclined to independent forms of travel (Zhang \& Hitchcock, 2014). The findings of prior research contradict the statistics of various industry sources which have unanimously pointed to the rise of the solo female travel market in Asia (Amadeus, 2013; eGlobal Travel Media, 2014). The incongruent findings can be attributed to the scant research on Asian female travellers, which may result in fractional understandings of this market. Despite this limitation, prior research has shed light on the diversity of women's travel experience. It suggests that women are not a homogenous group; hence, the experience of Asian women should not be subsumed under that of western women because of cultural differences. In fact, the appropriateness of interpreting the Asian tourist experience using a western-centric way of knowing has been questioned by scholars (Winter, 2009; Xu, Ding, \& Packer, 2008), who have all called for a critical approach that takes into account cultural pluralism. Similarly, gender scholars in tourism have urged for a culture-sensitive approach when considering non-western women's travel experience (Henderson \& Gibson, 2013).

\section{Review aims and objectives}

Given the scant and contradicting understandings of Asian female travellers, this study attempts to provide an overview of this under-researched area by synthesising existing literature that has considered Asian female travellers, and also attempts to identify knowledge gaps for future research. This review has no intention of taking an epiphanic approach (Weed, 2009) by counting past studies and claiming the one truth of Asian female travellers. Rather, it is designed to tell the stories of Asian women and their travel experiences as informed by existing literature. To address the western-centric criticism of tourism research, this review draws together multi-lingual references to provide a cultural reading of the historical and contemporary travel experiences of Asian women. The history of Asian women's mobility is emphasised because 'histories - stories and reconstructions of the past - are in fact illuminations of a present that would not be possible without this past' (Grosz, 2003, p. 15). While western women travellers in the nineteenth century have been frequently documented 
in female tourist studies (e.g., Jordan \& Gibson, 2005; Wilson \& Little, 2008), existing tourism research has rarely referred to Asian female travellers from the past. In fact, an investigation of the history of Asian tourism is listed by Winter (2009) at the top of the six urgent tasks for building a critical tourism scholarship in Asia. By looking into the past, we seek to trace the influence of deep-seated cultural values on gender performances and women's agency for subsequent comparison with Asian female travellers in the present. Accordingly, some implications for tourism research and management are provided.

\section{Methodology}

\section{The theoretical lens}

Travel experiences and gender are socially and culturally constructed (Aitchison, 2005), which requires female tourist research that is sensitive to its sociocultural context. This viewpoint echoes Henderson and Gibson's (2013) call for intersectional research where gender researchers are urged to consider social dimensions other than gender (e.g., ethnicity and culture). Therefore, the travel experience of Asian women is assumed to be different from that of western women. This assumption is informed by the authors' relativist ontological stance, in which realities are construed as social and cultural constructions. Accordingly, this study used a postcolonial feminist lens when interpreting Asian women's experience.

A key focus of postcolonial feminism is to make visible the complex social and political power relations that shape the culture and knowledge of the colonised (Khan et al., 2007; Wong, 2002). The resultant cultural values subsequently frame the gender norms and travel behaviour of women from postcolonial societies. Because the majority of Asian societies were once-colonised and/or are experiencing neo-colonialism through global capitalism and Third World tourism (Teo \& Leong, 2006), a postcolonial feminist perspective is deemed as a fitting lens in interpreting the experiences of Asian female travellers. Using this postcolonial feminist perspective, we decentred western orientation (Teo \& Leong, 2006), engaged in local ideologies and indigenous gender norms (Chambers \& Buzinde, 2015; Liu, 2011), and created an alternative discourse by giving voices to the marginalised others (Khan et al., 2007).

We recognise that Asian women are not a homogeneous group and that culture and the resultant gender norms are fluid and may be challenged, resisted, and transformed through 
Asian women's agency. Nevertheless, we are also aware that members of the oppressed group may accept their subordination as natural (Kincheloe \& McLaren, 2000). We acknowledge that the theoretical lens was influenced by the subjectivities of the research team, which consists of a western male and two Asian female researchers. However, it was this diverse socio-cultural background that has enabled us to critically examine and reflect on the colonisation of knowledge in understanding Asian women's experiences.

\section{Constructing 'Asia'}

To define Asia is by no means effortless, which may explain why many scholars have adopted a blanket definition for Asia in reference to the non-western others (du Cros, 2014; Teo \& Leong, 2006). It is convenient to employ the definition provided by the United Nations Statistics Division (UNSD), but that does not necessarily represent the 'truths' of Asia. For instance, Saudi Arabia is included in the UNSD's list of Asian countries, but it does not fit into the identities of other Asian people, which are increasingly centred on East Asia (Hall, 2009). We uphold Hall's (2009) viewpoint that the identities of Asians are socially constructed and are essentially products yielded from the othering process (Knight, 2000). This study construes Asia as situated in the eastern region, which includes China, Taiwan, Japan, Korea, and Southeast Asian countries, because of the comparable ideologies, cultural values, and gender norms (Knight, 2000). For instance, Confucianism and Islam are the two dominating ideologies in this region, shaping the patriarchal gender norms where women are expected to be obedient, domesticated, and family-oriented (Schröter, 2013; Tang \& Tang, 2001). Despite these broad similarities, internal differences within the region exist due to diverse ethnicities, religious practices, and uneven development status. This review does not intend to diminish the cultural and social complexities of the region but to reveal as many 'truths' of Asian female travellers as possible to fill the knowledge voids.

\section{The method}

This study is positioned as a synthesis of literature to provide an overview of what is known about Asian female travellers. Synthesis is both a process and a product where interpretations and evidences from various sources are integrated to advance understanding (Mays, Pope, \& Popay, 2005). Different methods to synthesis include narrative, qualitative, and quantitative approaches. While both narrative and qualitative approaches rely primarily on text to synthesise findings, qualitative synthesis (e.g., meta-ethnography) focuses on re-analysing 
findings from prior qualitative studies to generate new interpretations. Narrative synthesis, however, thematically analyses findings and interpretations from both qualitative and quantitative research without transforming the data (Mair, Ritchie, \& Walters, 2014; Mays et al., 2005). Furthermore, narrative synthesis differs from a traditional literature review by embracing a systematic and transparent approach in the literature extraction and the synthesis process (Mays et al., 2005; Popay et al., 2006). While narrative synthesis can be categorised as a systematic review tool, the emphasis on words differentiates it from quantitative systematic review and meta-analysis, which rely heavily on statistics (Mays et al., 2005). This study intends to bring together existing knowledge of Asian female travellers; but to trace the fragmentary understandings requires a review method that is instrumental in synthesising a wide range of studies with different research designs. This is where a narrative synthesis can contribute for its capacity in synthesising almost any type of research, as its main focus is to tell a trustworthy story based on the accounts of prior research (Mays et al., 2005; Popay et al., 2006).

This study looked beyond English-language literature to provide a comprehensive overview of the body of knowledge concerning Asian female travellers, and to address the western-centrism of tourism research. The literature search was conducted in four languages: English, simplified Chinese (China), traditional Chinese (Taiwan), and Malay. To ensure the extracted literature is of good quality, only academic journal articles that were peer reviewed were considered at the initial stage of the literature search. To identify relevant articles published in English-language tourism journals, we referred to the Australian Business Deans Council Journal Quality List (ABDC, 2013), which has been employed by past studies for its extensive coverage of tourism journals (Fennell, 2013; Hall, 2011). Chinese-language literature was extracted from the China Academic Journals Full-text Database (http://eng.oversea.cnki.net), and the Taiwan National Central Library Periodical Database (http://ncl.edu.tw) for papers written with traditional Chinese characters. Since there is no recognised database for Malay-language publications, the search was conducted on Google Scholar. The literature search began in December 2014 and finalised in October 2015, and the search terms used were female/woman/gender and traveller/tourist in all four languages. Such a study may consider, for example, Chinese women travel experience, but it may not necessarily mention 'Asian' in the paper. Hence, 'Asian' was excluded from the search terms. The identified literature was scrutinised to determine its relevance to Asian women. Table 1 
presents the literature search outcomes.

<Table 1 Here>

The initial search showed that extant literature concerning Asian female travellers is rather limited. While 479 papers were identified, only 65 papers that have investigated Asian women from a tourist perspective were extracted for analysis, and across these papers, only three (Chen, 2006; Guo, 2014; Liu, 2010) have considered the historical travel accounts of Asian women. Hence, we began to look beyond journal articles and tourism literature, and included literary works and historical travel writings. As attempted earlier, a systematic database search turned out to be ineffective in tracing these scant and dispersed studies. To address this deficiency, Google Scholar was used to identify the relevant literature. The search terms were modified to include another two keywords: an Asian country's name and a term to indicate time in the past, which included the early modern (before seventeenth century) and modern (seventeenth-mid-twentieth centuries) periods.

In stage two, 15 searches were conducted to cover China, Taiwan, Japan, Korea, and 11 Southeast Asian countries respectively. On average, a single search with any Asian country's name generated more than 15,000 titles, but it was not viable to analyse all the results. Existing guidelines for systematic review recognise no rigid cut-off point for a literature search, as it should be decided case-by-case (Page, 2008; Petticrew \& Roberts, 2006). In this study, the literature search discontinued when the listings began to indicate limited relevance to the study's intention, or when the search reached a saturation point (Petticrew \& Roberts, 2006). In addition to the three articles retrieved from the initial search, twelve books, nine journal articles, one conference paper, and one Master's thesis were extracted in the second stage. Figure 1 illustrates the literature search process and Tables 2 and 3 provide a summary of the literature profiles extracted from the two stages.

$<$ Figure 1 Here>

$<$ Tables 2 \& 3 Here>

This study referred to the narrative synthesis guidelines laid out by Popay et al. (2006) 
and the adapted version by Mair et al. (2014). The synthesis process consists of four steps: developing a theoretical foundation of the review; developing a preliminary synthesis of the extracted studies; exploring relationships across the studies; and evaluating the robustness of the synthesis (Popay et al., 2006). The first step was achieved through justifying the need for this review, setting the review aims and objectives, and elucidating the theoretical lens. This step was important, because it guided the synthesis process and the interpretation of the synthesis. Step two involved tabulating the extracted studies according to their research topics, contexts, methods, and findings, in order to explore the patterns of the literature. Although it was not the intention of this study to conduct a bibliometric analysis of the authors, an interesting observation has emerged: the majority of the English-language publications were led by Asian female authors.

In step three, the main focus was to identify similarities and differences across the extracted studies in interpreting the travel experiences of Asian women. Findings and explanations that are relevant to the interest of this review were identified and coded, and similar codes were grouped into themes. The synthesis outcomes from step three formed the basis of the remaining discussion, which is structured into three sections on a geographical basis: China and Taiwan, Korea and Japan, and Southeast Asia. Each section provides an overview of the travel experiences of Asian women from that region, both in the past and in the present, with attention to the predominant gender norms and socio-cultural context of different historical moments. Due to the narrative nature of this synthesis, the discussion focuses on telling the stories of Asian female travellers, rather than reporting the statistics of past studies. The discussion is informed by the 88 studies extracted earlier, but in the interests of brevity, not all studies are reported and cited in this review. The travel experiences of Asian women was read from a cultural perspective using a postcolonial feminist lens; hence, discussion of Asian gender norms and cultural values informed by references beyond the extracted literature are interwoven into the review to support the interpretations of the findings.

The robustness of the synthesis was evaluated based on the quality of the extracted literature, the transparency of the synthesis procedure, and the reflexivity of the researchers (Mair et al., 2014; Popay et al., 2006). The literature search and extraction was conducted systematically, and the synthesis process was reported. Most of the studies were obtained 
from academic journals; hence, these are credible references. Due to limited resources on the historical accounts, we also included the few available academic books, a conference paper, and a thesis. The credibility is still acceptable because these publications were likely to be peer reviewed. Besides, the first author, who is the main investigator of this study, practised memo writing throughout the synthesis process to critically reflect on the emerging concepts and assumptions made. Accordingly, it is argued that this synthesis is robust and credible. But, it does not mean that the synthesis is entirely reproducible, because the interpretations of the narratives from prior research are subjective in nature, and are influenced by the sociobiographical backgrounds of the researchers.

\section{Chinese female travellers}

\section{A historical review of Chinese female travellers}

Chinese women travelled as far back as the Han dynasty (206 BC-220 AD) (Zhang, 2005). The renowned poem of Ban Zhao (班昭), Dong Zheng Fu (東徵賦), is one of the first and few travel writings by Chinese women in the antiquity (Guo, 2008). The poem documented the journey of Ban Zhao, an influential female scholar, who followed her son to take up an official appointment. Travel of this nature was common in the past, from the antiquity to the early twentieth century, with daughters, wives, and mothers from aristocratic and official families following their male family members; these women were regarded as movable properties. Another common form of female travel was that undertaken by female courtesans who travelled with their clients to offer entertainment and companionship (Zhang, 2005). Although female courtesans suffered a relatively low social position, they shared a common characteristic with female family members of the gentry: they were subordinate to their male travel partners. These women did not have a voice in most aspects of travel and, as reflected in the limited female literary works, many women did not perceive their travel experiences as joyful encounters (Zhang, 2005).

The first Chinese female travelogue of travelling abroad is Guimao Lüxing Ji (癸印旅 行記), published in 1903 by Shan Shili (單士曐), who travelled with her ambassador husband (Guo, 2014; Widmer, 2006). Shan represented a prototype of the 'new woman' in the late Qing dynasty. She challenged the norms and transgressed the gender and class boundaries, because in a Confucian society, a noblewoman from the upper class would prefer not to travel abroad with her diplomat husband, as it would tarnish her identity as a private woman of the 
'inner chamber' or the boudoir, who was expected to stay at home and have limited contact with the world outside (Ying, 2006). Rather, the travel task was often undertaken by a courtesan or concubine who had a lower social status and was positioned as a public woman (Ying, 2006). Although Shan promoted female travel, education, and empowerment, she yearned for a non-western model of women's advancement that embraced Confucian virtues and Chinese female ideals (Guo, 2014). Her travelogue encouraged women to pursue education and travel in order to broaden their horizons so that they could become good wives and wise mothers. Following Shan's generation, new, modern women emerged. Against this social backdrop, female travel demonstrated increasing independence. While the accompanying female family members and courtesans remained as a typical form of female travel, many Chinese women began to travel independently for study. Lü Bicheng (呂碧城), an affluent and well-educated Chinese woman represented the frontier of Chinese female travellers in the 1920s. She travelled on her own in Europe and America for her own interest, and not as a companion like Shan (Fong, 2004).

Rapid social transformations have taken place following the end of World War II. This is reflected in the travel nature of Taiwanese women from the 1950s to the 1970s. Here, we focused on Taiwanese female travellers as tourism had not been active in Communist China until the late twentieth century. The relationship between Taiwan and Mainland China was hostile during the post-war period. Under that intense socio-political context, only people with special status (e.g., diplomats and their wives) could travel abroad in the 1950s (Lai, 2005). In the 1970s, the political and social context of Taiwan became relatively relaxed. It was also a time when the feminist movement began to germinate in Taiwan (Lin, 2008). A Taiwanese female writer, Sanmao (三毛) gained success and fame by publishing her adventures in the Sahara desert (Lai, 2005; Lang, 2003). Sanmao's travel experience, which was characterised as adventurous, nomadic, and romantic (Lang, 2003), was different to many other Asian female travellers discussed earlier. Resonating Lü, Sanmao was the subject of her own travel; she was not a follower or an accompanying wife. Besides, based on the successful reception of her travelogue, it appears that instead of frowning upon female travellers, Taiwanese society was relatively open to them in the 1970s. 


\section{Chinese female travellers in the present}

The prospect for the Chinese female travel market has been widely acknowledged in existing literature for its strong spending power (Li et al., 2011). Chinese female professionals and university students are two promising markets with high predilection to use disposable income on travel-related expenditures (Yang \& Zou, 2007). The travel motivations of Chinese women are diverse. Many women travel for pleasure and relaxation (Zheng \& Fan, 2007); others travel to broaden their knowledge and to reaffirm their social status ( $\mathrm{Li}$ et al., 2011). For some women, tourism provides a physical and mental space where they can escape from their everyday life, familial responsibility, and social expectation, where they can reflect and reconstruct their gender identity (Zhang \& Hitchcock, 2014).

However, a contradictory travel and gender attitude has been reported in prior research, where some Chinese women have expressed concerns about their domestic responsibilities when they travelled without their family (Zhang \& Hitchcock, 2014). Likewise, some older Chinese women even regard married women travelling with friends as inappropriate. These women are inclined to build another 'regular home' when on family holiday, where they continue to perform their care-taker duty as wives and mothers (Salazar $\&$ Zhang, 2013). On the contrary, some career-oriented women consider family holidays as an opportunity to perform their traditional gender roles, which have been hindered by their hectic daily life where they juggle work and family (Zhang \& Hitchcock, 2014). These contradictory gender performances reify the lingering breath of Confucian traditions in contemporary Chinese society (Guo, 2014).

Chinese women prefer to travel in small groups with friends and family, where they can have more freedom and an individualised itinerary compared to tour packages (Zheng \& Fan, 2007). A small percentage (less than 10\%) of women travelled alone, but the number is generally much lower compared to Chinese men (Yang \& Zou, 2007; Zhu, 2014). Many studies simply attributed this phenomenon to Chinese women's lack of self-reliance (Yang \& Zou, 2007; Zhao, 2013), without further investigations of the social and cultural construction of this dependent gender image. Likewise, safety emerges as an important consideration for Chinese women (Li, 2014; Zheng \& Fan, 2007). In particular, sexual harassment and assault was ranked as the top concern impacting women's travel experience. This implies that contemporary tourism landscape in China is still highly masculinised, because sexual-related 
risk can be construed as a representation of male dominance over female in using the tourism space (Gustafson, 1998).

While Chinese scholars commonly suggest that solo travel is not a preferred option for Chinese women because of safety concerns, Taiwanese scholars indicate an opposite scenario. Across the limited studies extracted from the Taiwanese journal database, many have investigated Taiwanese women who travel independently as backpackers and/or solo travellers (Tseng \& Li, 2004). While safety concerns have been noted in these studies, they have also reported the sense of empowerment and agency Taiwanese women gained from independent travel. The difference between women's travel attitudes in China and Taiwan warrants further investigations, as the gender norms in both societies have been influenced by Confucian traditions to a certain extent. Perhaps the social, economic, and political contexts in the post-war period have an important effect in shaping women's attitudes in postConfucian societies. As mentioned earlier, feminist movements already emerged in Taiwan in the 1970s, whereas China only opened its door to the world in 1978 (Lin, 2008). Hence, it is reasonable to assume that women from the capitalist democratic Taiwanese society are likely to embrace a more liberating type of travel earlier than women from the communist Mainland China, who started to travel much later. However, this assumption needs to be validated by further empirical study.

\section{Japanese and Korean female travellers}

\section{A historical review of Japanese and Korean female travellers}

Japanese and Korean female travellers are discussed in the same section because of their geographical proximity, shared ideology, and colonial history. Specifically, both societies were influenced by Confucianism, and Korea was colonised by Japan from 1910-1945 (Caprio, 2009). Little is known about Japanese and Korean female travellers in the early modern period due to the scant literature. However, a number of scholarly records concern Japanese women travelling in the modern period (seventeenth-early twentieth century). One explanation for the availability of female travel writings produced during that period was the growing emphasis on women's education in aristocratic families who were under the influence of Neo-Confucianism (Ko, Haboush, \& Piggott, 2003). Prior research concerning Japanese women's travel writings in the Tokugawa period (1603-1867) has revealed the restrictions on female mobility (Nenzi, 2006; Shiba, 2012). Travel undertaken by women was 
either for religious (e.g., pilgrimage), therapeutic (e.g., travelling to hot spring), or familial (e.g., accompanying male family members) purpose; women rarely undertook a trip for pleasure, and they were rarely the subject of travel. Even on pilgrimage, Japanese women were prohibited from entering certain sacred places (Fumiko, 2005). Female travel was regarded as undesirable in Japan, and there was a perception that one should divorce a wife who travelled excessively (Shiba, 2012) because women who transcended the traditional gender boundary were seen as a threat to social stability (Nenzi, 2008). Nevertheless, the fact that women did travel, regardless of the social expectations, indicates the agency of Japanese women. Ambivalent gender identity was reflected in Japanese women's travel accounts, which reveal how they struggled in confirming or resisting certain gender roles, especially when they were on the road and were freed from the confined role in households. Nenzi (2006) advises that travel offered Japanese women a chance for recreation (as in leisurerelated connotation) and re-creation (as in re-defining one's identity).

The earliest record of Korean female travellers identified in this review was the travel accounts of Kim Guem-Won, who travelled as a teenage boy in disguise and later travelled as an accompanying wife in the early nineteenth century (Kim, 2006). At the turn of the twentieth century, Korean schoolgirls and housewives were encouraged to undertake picnics and one-day excursions in order to enhance their physique and health, so that they could better bear children and nurture the next generation (Woo, 2008). This resonates with the gender hierarchy in Confucian societies where women were confined to the domesticated gender role. During the Japanese colonial period, group travel such as school excursions and study visits to Japan were possible for Korean women. There are also records of Korean women undertaking personal travel for study and sightseeing, but these women were either accompanied by, or accompanying, their male family members (Woo, 2008). Few Korean women had travelled independently; some of these exceptions include Park Hwa-Seong and Pahk Induk, who travelled alone in the 1930s (Choi, 2009; Woo, 2008). Pahk is probably the first Korean woman who had travelled extensively for study and missionary work in the United States and Europe (Choi, 2009).

\section{Japanese and Korean female travellers in the present}

The Japanese female travel market was the first to bloom in Asia occasioned by rapid internationalisation in the 1980s (Lang, O'Leary, \& Morrison, 1994). Since then, the 
characteristics of Japanese female travellers have changed tremendously. In the 1990s, Japanese female travellers were mainly housewives and office workers who preferred organised packaged tours. Their main travel motivations were to relax and escape from the daily routine, and to enhance their knowledge (Cai \& Combrink, 2000). Since the beginning of the twenty-first century, Japanese female travellers have been characterised as single and professional women who are adventurous and self-reliant; hence, they prefer independent travel over packaged tours (Fan \& Zheng, 2007; Hashimoto, 2000). Some Japanese women have a predilection for holiday romances, which Hashimoto (2000) interpreted as an alternate way for single Japanese women to resist patriarchal gender oppression, because they are expected to be submissive and subordinate to their husbands once they are married. Since then, limited publications have investigated Japanese female traveller in the past few years. The most recent article detected in this review was by Okazaki and Hirose (2009), who examined the gender effect in Japanese travel information search behaviour. However, their findings were not closely relevant to the scope of the review.

As a result of rapid economic growth and internationalisation, the Korean travel market has expanded significantly since 1989, when the overseas travel curb was removed (Bui, Wilkins, \& Lee, 2013). Although Korean women make up half of the overseas travel market (Kim, Lee, Lee, \& Song, 2012), little research has considered their travel experiences. Across the extracted studies, only two articles have investigated Korean tourists from a gender perspective: Kim et al. (2012) examined gender differences in a travel decisionmaking process, while Kim et al. (2013) conducted a gender comparison study of consumer behaviour in purchasing tourism services and products online. While statistical gender differences are identified in both studies, they have not contributed to an in-depth understanding of the experiences of Korean female travellers.

\section{Southeast Asian female travellers in the present}

Limited archival records have captured the experience of Southeast Asian women travelling in the past, because travel in this part of the world was not considered a pleasure but a necessary undertaking, such as travel for trade, labour, war, and pilgrimage, until the late nineteenth century (Winichakul, 2000). Moreover, the voices of Southeast Asian women have been largely silenced by history (Sarmento, 2012), which may further explain the scant female travel records. Until today, Southeast Asians have been commonly regarded as 
'immobile pre-modern participants of western tourism' (Alneng, 2002, p. 119). This is reflected in existing tourism research where the majority studies have approached Southeast Asian women as tourism suppliers rather than travellers. For example, past studies have examined Southeast Asian women's involvement in community-based tourism (Tran \& Walter, 2014) and sex tourism (Bernstein \& Shih, 2014). Only a few studies have considered Southeast Asian women as travellers (Asbollah et al., 2013; Chan, 2007).

Chan (2007) explores how Korean dramas motivate Singaporean women to visit South Korea. Although the study focuses on the film tourism industry perspective rather than the female travel experience, Chan's (2007) work provides an important frame of reference for the tourist profile of Singaporean women, who are generally young, single, and welleducated. Across both English- and Malay-language publications, Asbollah et al. (2013) provide the only research on Muslim female travellers from Southeast Asia. The authors reveal that these women are bounded by the 'cultural bubble': their travel behaviour is constrained by domesticated gender roles and religious practices, which include choosing destinations where women adhere to the Islamic dress code, and where halal food and prayer rooms are accessible. The authors also suggest that Malay Muslim female travellers tend to travel with family and not travel independently. This finding agrees with the gender practices in a traditional Muslim society, where women's mobility is relatively constrained. For instance, traditionalists opine that Muslim wives should seek permission from their husbands for participating in leisure activities outside the home (Othman, 2006). Nevertheless, Asbollah et al. (2013) speculate that this 'cultural bubble' may not survive the forces of modernisation and globalisation, and Muslim women are likely to search for more individualistic and independent travel experiences in the future. In sum, religion and culture constitute important lenses through which to understand the travel experiences of Asian women. Despite the scant scholarly literature, the footprint of Southeast Asian female travellers is visible on local news and community websites (e.g., Harian Kompas and Okezone in Indonesia) where travel advice for women is commonly posted, especially tips on safety, dress code, and solo travel.

\section{Discussion and conclusions}

The lack of research on the emerging and promising market of Asian female travellers forms the impetus of this review, which aims to provide a narrative synthesis of the historical and 
contemporary travel experiences of Asian women. Table 4 summarises the key findings of the synthesis.

$<$ Table 4 Here >

The findings of this synthesis are partial due to limited archival records and research concerning Asian female travellers. Besides, this review is restricted to literature written in English, Malay, and Chinese, and thus omits insights from other Asian literature published in Japanese, Korean, and other Southeast Asian languages. Despite this limitation, the findings have provided important 'puzzle pieces' in enhancing the understanding of Asian female travellers. Further research is needed to look for other missing puzzle pieces by reviewing literature in other languages and from other disciplines (e.g., cultural studies, gender studies, history, and philology).

This review contributes to existing understanding of Asian female travellers in three interrelated aspects: the agency of Asian women, the transformation of traveller identities, and the influence of cultural values on travel behaviour. Although the image of Asian women is commonly portrayed as submissive and non-autonomous (Schröter, 2013; Tang \& Tang, 2001), prior research has documented the agency of Asian women in resisting stereotypical and discriminatory gender practices through travel. Examples from the past include Shan Shili and Pahk Induk, who embraced travel when it was an inappropriate option for women, and when women were still confined to the domestic role (Choi, 2009; Guo, 2014). Examples in the present include solo female travellers from China, Taiwan, and Japan (Fan \& Zheng, 2007; Tseng \& Li, 2004; Zhu, 2014). These women have challenged the gender stereotype in which women are often seen as lacking independence and more inclined to travel in groups due to safety concerns. These accounts suggest that tourism space is more than a physical construction; it is a site for power negotiation (Aitchison, 2001), where Asian female travellers challenge the structural and cultural constraints imposed on them. Thus, the gendered tourism space provides an effective stage or a microcosm of reality to investigate the power relations underpinning the travel experiences of Asian women.

This review has also demonstrated the transition of the Asian female traveller identity/ies from a silent following wife, to an enthusiastic travelling wife, and eventually to 
the subject of her own travel. This transformation can be interpreted as a result of women's agency in resisting the gender norms. The shift of traveller identity was particularly prominent in the twentieth century where massive social transformations and feminist movements had been taken place, though in different forms and paces in the West and in different Asian societies (Tandon, 2008). While this transformation, that Asian women have begun to embrace travel, is evident, their travel behaviour is diverse due to cultural differences that exist among the various countries studied. For instance, Chinese women prefer travelling in groups (Yang \& Zou, 2007; Zheng \& Fan, 2007), whereas relatively more Taiwanese (Tseng \& Li, 2004) and Japanese women (Fan \& Zheng, 2007) embrace solo travel. Hence, it is important to take into consideration the social and cultural context when examining women's travel experiences.

Furthermore, the influence of cultural values on travel behaviour has been articulated in the findings. Confucian traditions and the patriarchal social structure restricted women's mobility and subordinated their travel experiences to those of men in the past. Scholars suggest that some gender stereotypes persist today and continue to impact the travel experiences of Asian women (Zhang, 2005; Zhang \& Hitchcock, 2014). For instance, some Chinese women regard a family holiday as an opportunity to perform their traditional gender roles, while others see a personal holiday as a way to escape from those roles (Zhang \& Hitchcock, 2014). Likewise, some Japanese women regard holiday romance as a way to resist the patriarchal gender role which they may take on after marriage (Hashimoto, 2000). These ambivalent gender identities and travel attitudes are a manifestation of the on-going reconstruction of Asian gender ideologies, where deep-seated cultural values and indigenous gender norms are challenged and modified by modern (or western) gender identities through the forces of neo-colonialism, globalisation, westernisation, and capitalisation. These ambivalent experiences reinforce the necessity to adopt a critical and culture-sensitive framework when studying the gendered Asian travellers.

Four gaps are identified with recommendations made for future research. First, there is an apparent dearth of research on Asian female travellers. Although Asian tourism research is rising (Winter, 2009), research on Asian female travellers has been almost absent from the international tourism discourse. Across 60 international tourism journals, this study identified less than 160 articles on women's travel experience, among which only 14 articles have 
considered Asian women, mainly led by Asian female authors. This finding reaffirms the marginalisation of women's travel experiences (Pritchard et al., 2007), which is further amplified regarding Asian women, and the colonisation of western perspective in international tourism research. The available historical records on Asian female travellers are even limited. The findings of the review suggest that Asian women were not encouraged to travel independently for leisure purpose in the past (Nenzi, 2008; Ying, 2006). For those who managed to travel and write about the travel experience, their literary works were often considered as immature and hence, incomparable with men's work (Guo, 2014), which may partially explain the scant record. The dearth of literature implies a huge research opportunity, not only to fill the knowledge void concerning women travellers in the past and in the present, but also to decolonise the tourism field. This is especially relevant to our field because contemporary tourism is often regarded as a product of western civilisation (Chambers, 2010). Specifically, it is regarded as an outcome from the growth of western industrial capitalism and rail transportation. The root of contemporary tourism can be traced back to the European elite excursions of the eighteenth and nineteenth centuries. As a result, existing international tourism literature often overemphasises western travellers, overlooking the existence of other travel traditions and histories (Chambers, 2010). While this review has contributed a non-western perspective, more research is needed to further diversify the field at an international level.

Second, while local publications (e.g., Chinese journals) may have a stronger interest in this area, the extracted studies appear to rely heavily on a positivist paradigm and descriptive statistics. Few authors have questioned the colonial legacy of tourism and the influence of neo-colonialism on the (re)construction of Asian gender norms. Most of these studies pay limited attention to the local context and feminist theories, neglecting that gender is a socio-cultural construction. As a result, they are unable to explain the complexities of gendered tourist behaviour. Rather, prejudiced assumptions were made; for example, women are inherently dependent, and hence less fond of solo holidays and adventurous activities (Zhao, 2013); or shopping is a natural behaviour for women (Yang \& Zou, 2007). Therefore, future research that will prioritise the construction of theoretical foundations for researching Asian women and tourism is encouraged. A critical perspective is crucial for gender-related tourism research in Asia, especially in decolonizing the hegemony of western and androcentric epistemologies in understanding the experiences of Asian female travellers. As 
demonstrated in this study, a postcolonial feminist perspective may be an instrumental theoretical point of departure in researching Asian women's travel experience because it questions the (neo-)colonial legacy in everyday structure and process (tourism included); it challenges the hegemonic discourse that privileges male perspective; it critiques the representativeness of white feminism for women of colour; and it gives voice to others (Khan et al., 2007).

Third, future research that will explore female travellers from Southeast Asian countries, such as Thailand, Vietnam, and Indonesia is also encouraged. With strong growing economies, coupled with the large population and the rise of its middle class, Southeast Asia has emerged as a potential outbound market (World Tourism Organization, 2013). Despite this market prospect, little research has considered women's travel experience in this region; most of the existing tourism literature has focused on Southeast Asian women from a supplier perspective (Bernstein \& Shih, 2014; Tran \& Walter, 2014). Hence, research on female travellers from this sub-region is highly warranted to redress the misconception of immobility highlighted by Alneng (2002).

Fourth, another rewarding area to investigate is Asian solo female travellers. We argue that travelling alone is one example of resisting gender stereotypes, both in the past and in the present, and both in the West and in Asia. Although some scholars (e.g., Zhang \& Hitchcock, 2014) purport that Asian women are less likely to travel alone, the footprint of Asian solo female travellers is noticeable in the extant literature (Fan \& Zheng, 2007; Tseng \& Li, 2004; Zhu, 2014). Nevertheless, few studies have explored the experiences of Asian solo female travellers who have managed to break through the social and cultural bubble. The dearth of research implies an uncharted yet significant area of research, especially in understanding how cultural identities and gender stereotypes inform travel behaviour.

While the main aim of the narrative review was not to provide managerial solutions, some insights can still be drawn from the findings. As discussed, female travellers make up a large segment of the contemporary travel market and women's participation in tourism is booming in the emerging market. Hence, understanding the needs and priorities of Asian female travellers would be an important underpinning to tourism marketing initiatives. Firstly, the industry will particular benefit from the understanding that the Asian female travel 
market is neither static nor homogeneous, resulting in a need to diversify tourism products to cater to the varied and changing needs of Asian female travellers. Based on the review, the travel behaviour of Asian women can be broadly divided into two camps: the traditional and the independent. The traditional Asian female travellers tend to travel with their families where they continue to perform the caretaker role. Travel packages that contain family travel activities, multi-lingual parenting programmes, a travelling nanny for women with young children (or a nurse for women travelling with aged parents), and relaxation spa packages may be appealing to this market because they create opportunities for women to spend time with family but at the same time give women some 'me-time' to unwind and be pampered. Tourism providers are likely to thrive in the Muslim travel market by being sensitive to the Asian cultural norms and religious practices, such as by providing modest tourism activities, halal food, and prayer rooms (Abodeeb, Wilson, \& Moyle, 2015; Asbollah et al., 2013). For travellers who prefer an independent form of travel, destination managers and marketers could create and promote a safe and friendly space for women to undertake adventure and to explore the self, since safety was identified as the main concern preventing Asian women from travelling independently. Furthermore, industry players are recommended to look beyond the relatively mature markets within the region such as the Chinese and Japanese female travel markets. Rather, other developing economies in Southeast Asia are emerging to become promising outbound markets in the future with increasing discretionary income as a result of rapid industrialisation. This growth will be further enhanced by the increasing access to travel with low-cost carrier sector booming in this region.

Finally, a number of unanswered questions, which we are unable to address within the current scope, have arisen from the review. These questions include how to deal with situations where subordination is accepted as natural, such as the gender and social constraints faced by Asian female travellers when using the male-privileged tourism space; how to identify the influence of western travel ideology/ies on Asian female travellers; and how to effectually engage local epistemologies in gender studies in tourism. We hope future research can attend to these issues, and further contribute to the understanding of Asian female travellers by discovering other missing puzzle pieces. In sum, this study is a fundamental step in setting a solid platform for further research in a field which will increasingly be influential for tourism marketing and management. 


\section{References}

ABDC. (2013). ABDC journal quality list 2013. Retrieved November 26, 2014, from http://www.abdc.edu.au/pages/abdc-journal-quality-list-2013.html

Abodeeb, J., Wilson, E., \& Moyle, B. (2015). Shaping destination image and identity: insights for Arab tourism at the Gold Coast, Australia. International Journal of Culture, Tourism and Hospitality Research, 9(1), 6-21. doi: 10.1108/IJCTHR-062014-0051

Aitchison, C. (2001). Theorizing Other discourses of tourism, gender and culture: Can the subaltern speak (in tourism)? Tourist Studies, 1(2), 133-147.

Aitchison, C. (2005). Feminist and gender perspectives in tourism studies: The social-cultural nexus of critical and cultural theories. Tourist Studies, 5(3), 207-224. doi: $10.1177 / 1468797605070330$

Alneng, V. (2002). The modern does not cater for natives: Travel ethnography and the conventions of form. Tourist Studies, 2(2), 119-142. doi:

$10.1177 / 146879702761936626$

Amadeus. (2013). Shaping the future of travel in Asia Pacific: The big four travel effects. Retrieved April 4, 2015, from www.apacwhitepapers.amadeus.com

Andrews, D. (2015). In her own way. TTG Asia. Retrieved November 19, 2015, from http://ttgasia.com/article.php?article_id=23173

Apostolopoulos, Y., Sönmez, S., \& Timothy, D.J. (Eds.). (2001). Women as producers and consumers of tourism in developing regions. Westport, CT: Praeger.

Asbollah, A.Z.B., Lade, C., \& Michael, E. (2013). The tourist's gaze: From the perspective of a Muslim woman. Tourism Analysis, 18(6), 677-690. doi: $10.3727 / 108354213 X 13824558188703$

Bernstein, E., \& Shih, E. (2014). The erotics of authenticity: Sex trafficking and "reality tourism" in Thailand. Social Politics: International Studies in Gender, State \& Society, 21(3), 430-460. doi: 10.1093/sp/jxu022

Bond, M. (2015). Women travel statistics explained by travel expert. Retrieved November 14, 2015, from http://gutsytraveler.com/women-travel-statistics-2/

Bowen, H.E. (2005). Female travelers-Part I [Special issue]. Tourism Review International, 9(2).

Bowen, H.E. (2008). Female travelers-Part II [Special issue]. Tourism Review International, 12(2). 
Bui, H.T., Wilkins, H.C., \& Lee, Y.-S. (2013). The 'imagined West' of young independent travellers from Asia. Annals of Leisure Research, 16(2), 130-148. doi: $10.1080 / 11745398.2013 .791227$

Cai, L.A., \& Combrink, T.E. (2000). Japanese female travelers - A unique outbound market. Asia Pacific Journal of Tourism Research, 5(1), 16-24. doi: $10.1080 / 10941660008722055$

Caprio, M. E. (2009). Japanese assimilation policies in colonial Korea, 1910-1945. Seattle WA: University of Washington Press.

Chambers, E. (2010). Native tours: The anthrogology of travel and tourism (2nd ed.). Long Grove, IL: Waveland Press.

Chambers, D., \& Buzinde, C. (2015). Tourism and decolonisation: Locating research and self. Annals of Tourism Research, 51(0), 1-16. doi: 10.1016/j.annals.2014.12.002

Chan, B. (2007). Film-induced tourism in Asia: A case study of Korean television drama and female viewers' motivation to visit Korea. Tourism Culture \& Communication, 7(3), 207-224. doi: 10.3727/109830407782212510

Chen, S.-R. (2006). Gui ge yu shi jie de peng zhuang: Shan Shili lv xing shu xie de xing bie yi shi yu di guo ning shi [Collisions between the chamber and the world: The gender consciousness and the gaze of empire in Shan Shili's travel writings]. Zhang Hua Shi Da Guo Wen Xue Zhi, 13, 257-282.

Choi, H. (2009). Gender and mission encounters in Korea: New women, old ways. Berkeley, CA: University of California Press.

Craik, J. (1997). The culture of tourism. In C. Rojek \& J. Urry (Eds.), Tourism cultures: Transformations of travel and theory (pp. 113-136). London: Routledge.

du Cros, H. (2014). New models of travel behavior for independent Asian youth urban cultural tourists (Working Paper No. 217). Singapore: National University of Singapore, Asia Research Institute.

eGlobal Travel Media. (2014, April 29). Luxperience 2014 and the rising importance of the female travel market in Asia Pacific. Retrieved January 5, 2015, from http://www.eglobaltravelmedia.com.au/luxperience-2014-and-the-rising-importanceof-the-female-travel-market-in-asia-pacific/

Fan, X-L, and Zheng, X-M. (2007). Wen hua yi hua dui ri ben dan shen ji sheng zu nv xing lv you xing wei de ying xiang [The impact of cultural alienation on the travel behaviour of Japanese single women]. Hиа Qiao Da Хие Хие Bao, 3, 45-49. 
Fennell, D. (2013). The ethics of excellence in tourism research. Journal of Travel Research, 52(4), 417-425. doi: 10.1177/0047287512475220

Fong, G.S. (2004). Alternative modernities, or a classical woman of modern China: The challenging trajectory of Lü Bicheng's (1883-1943) life and Song lyrics. Nan Nü, 6(1), 12-59. doi: $10.1163 / 1568526042523227$

Frohlick, S. (2013). Sexuality, women, and tourism: Cross-border desires through contemporary travel. Oxon: Routledge.

Fumiko, M. (2005). Female pilgrims and Mt. Fuji: Changing perspectives on the exclusion of women. Monumenta Nipponica, 60(3), 339-391. doi: 10.2307/25066386

Grosz, E. (2003). Histories of the present and future: Feminism, power, bodies. In J.J. Cohen \& G. Weiss (Eds.), Thinking the limits of the body (pp. 13-24). Albany, NY: State University of New York Press.

Guo, Y. (2008). Nv lv shu xie zhong de shi jian, kong jian yu zi wo zhui xun - Chong du ban zhao <Dong Zheng Fu> [The time, space and self-searching in female travel writings - Reading of Ban Zhao's "Dong Zheng Fu"]. Dong Hai Da Xue Zhong Wen Xue Bao, 20, 89-104.

Guo, Y. (2014). Chinese women and travel: Historical and contemporary experiences. Annals of Tourism Research, 46, 179-181. doi: 10.1016/j.annals.2014.02.004

Gursoy, D., \& Sandstrom, J.K. (2014). An updated ranking of hospitality and tourism journals. Journal of Hospitality \& Tourism Research. doi:

$10.1177 / 1096348014538054$

Gustafson, P.E. (1998). Gender differences in risk perception: Theoretical and methodological perspectives. Risk Analysis, 18(6), 805-811. doi: 10.1111/j.15396924.1998.tb01123.x

Hall, C.M. (2009). 'A long and still-unfinished story?' Constructing and defining Asian regionalisms. In T. Winter, P. Teo \& T.C. Chang (Eds.), Asia on tour: Exploring the rise of Asian tourism (pp. 21-33). Abingdon: Routledge.

Hall, M.C. (2011). Publish and perish? Bibliometric analysis, journal ranking and the assessment of research quality in tourism. Tourism Management, 32(1), 16-27. doi: 10.1016/j.tourman.2010.07.001

Harris, C., \& Wilson, E. (2007). Travelling beyond the boundaries of constraint: Women, travel and empowerment. In A. Pritchard, N. Morgan, I. Ateljevic \& C. Harris (Eds.), Tourism \& gender: Embodiment, sensuality and experience. Oxfordshire: CABI. 
Hashimoto, A. (2000). Young Japanese female tourists: An in-depth understanding of a market segment. Current Issues in Tourism, 3(1), 35-50. doi: $10.1080 / 13683500008667865$

Henderson, K.A., \& Gibson, H.J. (2013). An integrative review of women, gender, and leisure: Increasing complexities. Journal of Leisure Research, 45(2), 115-135.

Huang, R. (2006). A study of gender differences: The travel behaviour of Chinese international students studying in the UK. Tourism, 54(1), 63-69.

Jordan, F., \& Gibson, H. (2005). "We're not stupid...But we'll not stay home either": Experiences of solo women travelers. Tourism Review International, 9(2), 195-211. doi: $10.3727 / 154427205774791663$

Khan, K.B., McDonald, H., Baumbusch, J.L., Kirkham, S.R., Tan, E., \& Anderson, J.M. (2007). Taking up postcolonial feminism in the field: Working through a method. Women's Studies International Forum, 30(3), 228-242. doi: 10.1016/j.wsif.2007.03.004

Kim, J. (2014, May 9). I want to be alone! 72 percent of American women will vacation solo this year. Yahoo! Travel. Retrieved from https://www.yahoo.com/travel/the-rise-ofthe-solo-lady-traveler-by-the-numbers-85084024117.html

Kim, M.-J., Lee, C.-K., \& Chung, N. (2013). Investigating the role of trust and gender in online tourism shopping in South Korea. Journal of Hospitality \& Tourism Research, 37(3), 377-401. doi: 10.1177/1096348012436377

Kim, M.-J., Lee, M.J., Lee, C.-K., \& Song, H.-J. (2012). Does gender affect Korean tourists' overseas travel? Applying the model of goal-directed behavior. Asia Pacific Journal of Tourism Research, 17(5), 509-533. doi: 10.1080/10941665.2011.627355

Kim, T.-J. (2006). Korean travel literature. Seoul: Ewha Womans University Press.

Kincheloe, J., \& McLaren, P. (2000). Rethinking critical theory and qualitative research. In N.K. Denzin \& Y.S. Lincoln (Eds.), Handbook of qualitative research (2nd ed., pp. 279-313). Thousand Oaks, CA: Sage.

Knight, N. (2000). Thinking about Asia: An Australian introduction to East and Southeast Asia. Hindmarsh: Crawford House.

Ko, D., Haboush, J.K., \& Piggott, J.R. (Eds.). (2003). Women and Confucian cultures in premodern China, Korea, and Japan. Los Angeles, CA: University of California Press. 
Lai, Y.-H. (2005). The study of female's space travel experiences: By the examples of travel literature of Taiwanese female novelists (1949-2000). Unpublished Master's thesis, Chung Yuan Christian University, Taiwan.

Lang, C.-T., O'Leary, J.T., \& Morrison, A.M. (1994). Activity segmentation of Japanese female overseas travelers. Journal of Travel \& Tourism Marketing, 2(4), 1-22. doi: 10.1300/J073v02n04_01

Lang, M. (2003). San Mao and Qiong Yao, a "popular" pair. Modern Chinese Literature and Culture, 15(2), 76-120. doi: 10.2307/41490905

Li, J. (2014). Social psychology study on the sex security of female tourists: Based on the sexual harassment of a Thailand. The Chinese Journal of Human Sexuality, 23(8), 8790. doi: 10.3969 /j.issn.1672-1993.2014.08.032

Li, M., Wen, T., \& Leung, A. (2011). An exploratory study of the travel motivation of Chinese female outbound tourists. Journal of China Tourism Research, 7(4), 411-424. doi: 10.1080/19388160.2011.627020

Lin, F.-M. (2008, April 18-20). Women's movement and the development of civil society in Taiwan. Paper presented at the 5th Annual Conference of European Association of Taiwan Studies, Prague, Czech.

Liu, J.H. (2011). Asian epistemologies and contemporary social psychological research. In N.K. Denzin \& Y.S. Lincoln (Eds.), The sage handbook of qualitative research (4th ed., pp. 213-226). Thousand Oaks, CA: Sage.

Liu, Y.-S. (2010). Shan Shili gui mao lv xing ji de nv quan lun shu [On the female rights in Shan Shili's guimao voyage]. Guo Wen Tian Di, 26(2), 113-128.

Mair, J., Ritchie, B.W., \& Walters, G. (2014). Towards a research agenda for post-disaster and post-crisis recovery strategies for tourist destinations: A narrative review. Current Issues in Tourism, 1-26. doi: 10.1080/13683500.2014.932758

Mays, N., Pope, C., \& Popay, J. (2005). Systematically reviewing qualitative and quantitative evidence to inform management and policy-making in the health field. Journal of Health Services Research \& Policy, 10(suppl 1), 6-20. doi: $10.1258 / 1355819054308576$

Nenzi, L. (2006). Women's travel narratives in early modern Japan: Genre imperatives, gender consciousness and status questioning. In J.A. Fogel (Ed.), Traditions of East Asian travel (pp. 20-43). New York: Berghahn Books. 
Nenzi, L. (2008). Excursion in identity: Travel and the intersection of place, gender, and status in Edo Japan. Honolulu, HI: University of Hawai'i Press.

Othman, N. (2006). Muslim women and the challenge of Islamic fundamentalism/extremism: An overview of Southeast Asian Muslim women's struggle for human rights and gender equality. Women's Studies International Forum, 29(4), 339-353. doi: 10.1016/j.wsif.2006.05.008

Page, D. (2008). Systematic literature searching and the bibliographic database haystack. The Electronic Journal of Business Research Methods, 6(2), 171-180.

Petticrew, M., \& Roberts, H. (2006). Systematic reviews in the social sciences: A practical guide. Malden, MA: Blackwell.

Popay, J., Roberts, H., Sowden, A., Petticrew, M., Arai, L., Rodgers, M., . . Duffy, S. (2006). Guidance on the conduct of narrative synthesis in systematic reviews: A product from the ESRC methods programme. Version 1.

Pritchard, A., Morgan, N., Ateljevic, I., \& Harris, C. (Eds.). (2007). Tourism, gender, embodiment and experience. Oxfordshire: CABI.

Salazar, N.B., \& Zhang, Y. (2013). Seasonal lifestyle tourism: The case of Chinese elites. Annals of Tourism Research, 43(0), 81-99. doi: 10.1016/j.annals.2013.04.002

Sarmento, C. (2012). Heading east this time: Critical readings on gender in Southeast Asia. In C. Sarmento (Ed.), Eastwards / westwards: Which direction for gender studies in the 21st century (pp. 143-165). Newcastle: Cambridge Scholars.

Schröter, S. (Ed.). (2013). Gender and Islam in Southeast Asia: Women's rights movements, religious resurgence and local traditions. Leidon: Brill.

Shiba, K. (2012). Literary creations on the road: Women's travel diaries in early modern Japan (M. Ezaki, Trans.). Lanham, MD: University Press of America.

Swain, M.B. (1995). Gender in tourism [Special issue]. Annals of Tourism Research, 22(2).

Swain, M.B., \& Momsen, J.H. (Eds.). (2002). Gender/tourism/fun(?). New York: Cognizant Communication.

Tandon, N. (2008). Feminisim: A paradigm shift. Delhi, India: Atlantic.

Tang, T.N., \& Tang, C.S. (2001). Gender role internalization, multiple roles, and Chinese women's mental health. Psychology of Women Quarterly, 25(3), 181-196. doi: $10.1111 / 1471-6402.00020$

Teo, P., \& Leong, S. (2006). A postcolonial analysis of backpacking. Annals of Tourism Research, 33(1), 109-131. doi: 10.1016/j.annals.2005.05.001 
Tran, L., \& Walter, P. (2014). Ecotourism, gender and development in northern Vietnam. Annals of Tourism Research, 44, 116-130. doi: 10.1016/j.annals.2013.09.005

Tseng, P.-F., \& Li, C.-J. (2004). Bon voyage: The restless insecurity encroaching female backpackers. Journal of Hospitality and Home Economics, 1(2), 127-142.

Weed, M. (2009). Progress in sports tourism research? A meta-review and exploration of futures. Tourism Management, 30(5), 615-628. doi: 10.1016/j.tourman.2009.02.002

Widmer, E. (2006). Foreign travel through a woman' eyes: Shan Shili's Guimao Lüxing Ji in local and global perspective. The Journal of Asian Studies, 65(04), 763-791. doi: $10.1017 / \mathrm{S} 0021911806001598$

Wilson, E., \& Harris, C. (2006). Meaningful travel: Women, independent travel and the search for self and meaning. Tourism, 54(2), 161-172.

Wilson, E., \& Little, D.E. (2005). A 'relative escape'? The impact of constraints on women who travel solo. Tourism Review International, 9(2), 155-175. doi: $10.3727 / 154427205774791672$

Wilson, E., \& Little, D.E. (2008). The solo female travel experience: Exploring the 'geography of women's fear'. Current Issues in Tourism, 11(2), 167-186. doi: $10.2167 / \operatorname{cit} 342.0$

Winichakul, T. (2000). The others within: Travel and ethno-spatial differentiation of Siamese subjects 1885-1910. In A. Turton (Ed.), Civility and savagery: Social identity in Tai states (pp. 38-62). Surrey: Curzon Press.

Winter, T. (2009). Asian tourism and the retreat of anglo-western centrism in tourism theory. Current Issues in Tourism, 12(1), 21-31. doi: 10.1080/13683500802220695

Wong, Y.-L.R. (2002). Reclaiming chinese women's subjectivities: Indigenizing “social work with women" in China through postcolonial ethnography. Women's Studies International Forum, 25(1), 67-77. doi: 10.1016/S0277-5395(02)00222-4

Woo, M.-Y. (2008). Historical places of the colonial period through the eyes of a female traveler. The Review of Korean Studies, 11(4), 105-126.

World Tourism Organization. (2013). UNWTO/Tourism Australia report highlights the potential of South-East Asian outbound tourism. Retrieved May 6, 2015, from http://media.unwto.org/press-release/2013-04-29/unwtotourism-australia-reporthighlights-potential-south-east-asian-outboun 
Xu, H., Ding, P., \& Packer, J. (2008). Tourism research in China: Understanding the unique cultural contexts and complexities. Current Issues in Tourism, 11(6), 473-491. doi: $10.1080 / 13683500802475737$

Yang, E. C. L. (2016). Risk perception of Asian solo female travelers: An autoethnographic approach. In C. Khoo-Lattimore \& E. Wilson (Eds.), Women and travel: Historical and contemporary perspectives. Oakville, Canada: Apple Academic Press.

Yang, Y., \& Zou, S.S. (2007). Nv da xue sheng lv xing xing wei te zheng fen xi ji shi chang kai fa dui ce [A marketing analysis of the travel behaviour of female university student]. Rural Economy and Science-Technology, December, 67-68.

Ying, H. (2006). 'Would that I were Marco Polo': The travel writing of Shan Shili (18561943). In J.A. Fogel (Ed.), Traditions of East Asian travel (pp. 144-166). New York: Berghahn Books.

Zhang, J. (2005). Zhong guo gu dai nu xing chu you xing wei te zheng xin tan [An exploration of the travel behaviour of ancient Chinese women]. Zhong Hua Wen Hua Lun Tan, 2, 27-32.

Zhang, Y., \& Hitchcock, M.J. (2014). The Chinese female tourist gaze: A netnography of young women's blogs on Macao. Current Issues in Tourism, Advance online publication. doi: 10.1080/13683500.2014.904845

Zhao, J. (2013). Shi fan yuan xiao shuo shi yan jiu sheng lv you xing wei xing bie cha yi fen xi [A gender comparison of the travel behaviour of postgraduate student from teaching universities]. Journal of Hebei Tourism Vocational College, 18(1), 29-32.

Zheng, X.-M., \& Fan, X.-L. (2007). On developing feminine tourist market in feminine economy era. Tourism Science, 21(3), 65-71.

Zhu, J. (2014). Da xue sheng lv you xiao fei xing wei xing bie cha yi yan jiu [Gender comparison of univserity student travel behaviour]. Tibetan Plateau Forum, 2(2), 115121. 
Table 1. Initial literature search outcomes.

\begin{tabular}{|c|c|c|c|c|}
\hline Languages & Sources & $\begin{array}{l}\text { No. of Papers } \\
\text { Identified }\end{array}$ & Exclusion Criteria & $\begin{array}{l}\text { No. of Papers } \\
\text { Extracted }\end{array}$ \\
\hline English & $\begin{array}{l}60 \text { Tourism Journals } \\
\text { listed in ABDC List }\end{array}$ & 278 & $\begin{array}{l}\text { - Not focusing on Asian women } \\
\text { - Not relevant to tourism } \\
\text { - Focusing on female hosts }\end{array}$ & 14 \\
\hline $\begin{array}{l}\text { Simplified } \\
\text { Chinese }\end{array}$ & $\begin{array}{l}\text { China Academic } \\
\text { Journals Full-text } \\
\text { Database }\end{array}$ & 141 & $\begin{array}{l}\text { rather than female travellers } \\
\text { - Not peer reviewed journals }\end{array}$ & 44 \\
\hline $\begin{array}{l}\text { Traditional } \\
\text { Chinese }\end{array}$ & $\begin{array}{l}\text { Taiwan National } \\
\text { Central Library } \\
\text { Periodical Database }\end{array}$ & 44 & & 7 \\
\hline Malay & Google Scholar & 16 & & 0 \\
\hline Total & & 479 & & 65 \\
\hline
\end{tabular}


Table 2. Profiles of the literature by publication types.

\begin{tabular}{lccccc}
\hline Publication Types & No. of Papers & $1980-1989$ & $1990-1999$ & $2000-2009$ & $2010-2015$ \\
\hline $\begin{array}{l}\text { Contemporary Accounts } \\
\text { Journal Articles }\end{array}$ & $\mathbf{6 2}$ & $\mathbf{0}$ & $\mathbf{3}$ & $\mathbf{2 7}$ & $\mathbf{3 2}$ \\
- English & 14 & & 2 & 6 & 6 \\
- Chinese & 48 & & 1 & 21 & 26 \\
Historical Accounts & $\mathbf{2 6}$ & $\mathbf{1}$ & $\mathbf{3}$ & $\mathbf{1 9}$ & $\mathbf{3}$ \\
Conference Paper (English) & 1 & & & 1 & \\
Books / Book Chapters (English) & 12 & & 2 & 9 & 1 \\
Journal Articles (English) & 7 & 1 & 1 & 4 & 1 \\
Journal Articles (Chinese) & 5 & & & 4 & 1 \\
Thesis (Chinese) & 1 & & & 1 & \\
Total & $\mathbf{8 8}$ & $\mathbf{1}$ & $\mathbf{6}$ & $\mathbf{4 6}$ & $\mathbf{3 5}$ \\
\hline
\end{tabular}


Table 3. Profiles of the literature by research types.

\begin{tabular}{lccc}
\hline Types of Publication & No. of Paper & English & Chinese \\
\hline Empirical Research & $\mathbf{4 6}$ & $\mathbf{1 4}$ & $\mathbf{3 2}$ \\
By Research Focus & 25 & 8 & 17 \\
- Women-Focused & 21 & 6 & 15 \\
- Gender Comparison & & & 25 \\
By Methodology & 31 & 6 & 5 \\
- Quantitative & 11 & 6 & 2 \\
- Qualitative & 4 & 2 & $\mathbf{2 2}$ \\
- Mixed Methods & & & 10 \\
Non-empirical Research & $\mathbf{4 2}$ & $\mathbf{2 0}$ & 6 \\
- Traditional Literature Reviews & 13 & 3 & 6 \\
- Analyses of Travel Writings & 12 & 6 & \\
- Short Commentaries & 6 & 2 & \\
- Biographies & 2 & 6 & \\
- Historical Analyses of Asia & 6 & 3 & $\mathbf{5 4}$ \\
- Anthologies of Literary Works & 3 & $\mathbf{3 4}$ & \\
Total & $\mathbf{8 8}$ & & \\
\hline
\end{tabular}


Table 4. Summary of the findings.

\begin{tabular}{|c|c|c|c|}
\hline & Chinese Women & Japanese \& Korean Women & Southeast Asian Women \\
\hline $\begin{array}{c}\text { Before } \\
\text { seventeenth } \\
\text { century }\end{array}$ & \multirow[t]{2}{*}{ Travelled as companions } & Unknown; limited literature & \multirow[t]{3}{*}{ Unknown; limited literature } \\
\hline $\begin{array}{l}\text { Seventeenth } \\
\text { to } \\
\text { nineteenth } \\
\text { centuries }\end{array}$ & & $\begin{array}{l}\text { Travelled as companions } \\
\text { Travelled for pilgrimage and } \\
\text { therapeutic purpose } \\
\text { Female travel was regarded } \\
\text { as undesirable }\end{array}$ & \\
\hline $\begin{array}{l}\text { Early to } \\
\text { mid- } \\
\text { twentieth } \\
\text { century }\end{array}$ & \multicolumn{2}{|c|}{$\begin{array}{l}\text { Travelled as companions } \\
\text { Female travel was directed to women's traditional gender roles } \\
\text { Few travelled independently }\end{array}$} & \\
\hline Present day & $\begin{array}{l}\text { Chinese: } \\
\text { Female professionals and } \\
\text { students } \\
\text { Prefer travelling in small } \\
\text { groups } \\
\text { Contradictory travel and } \\
\text { gender attitudes are observed }\end{array}$ & $\begin{array}{l}\text { Japanese: } \\
\text { 1990s: Housewives and } \\
\text { office workers who preferred } \\
\text { organised package tours } \\
\text { 2000s: Single and } \\
\text { professional women who } \\
\text { prefer independent travel, } \\
\text { and have a predilection for } \\
\text { holiday romance }\end{array}$ & $\begin{array}{l}\text { Muslim, Malay: } \\
\text { Travel behaviour bounded } \\
\text { by traditional gender roles } \\
\text { and religious practices } \\
\text { Prefer travelling with } \\
\text { families }\end{array}$ \\
\hline & $\begin{array}{l}\text { Taiwanese: } \\
\text { Prefer independent travel }\end{array}$ & $\begin{array}{l}\text { Korean: } \\
\text { Unknown; limited literature }\end{array}$ & $\begin{array}{l}\text { Singaporean: } \\
\text { Young, single, well- } \\
\text { educated women }\end{array}$ \\
\hline
\end{tabular}


Figure 1. The literature search process.

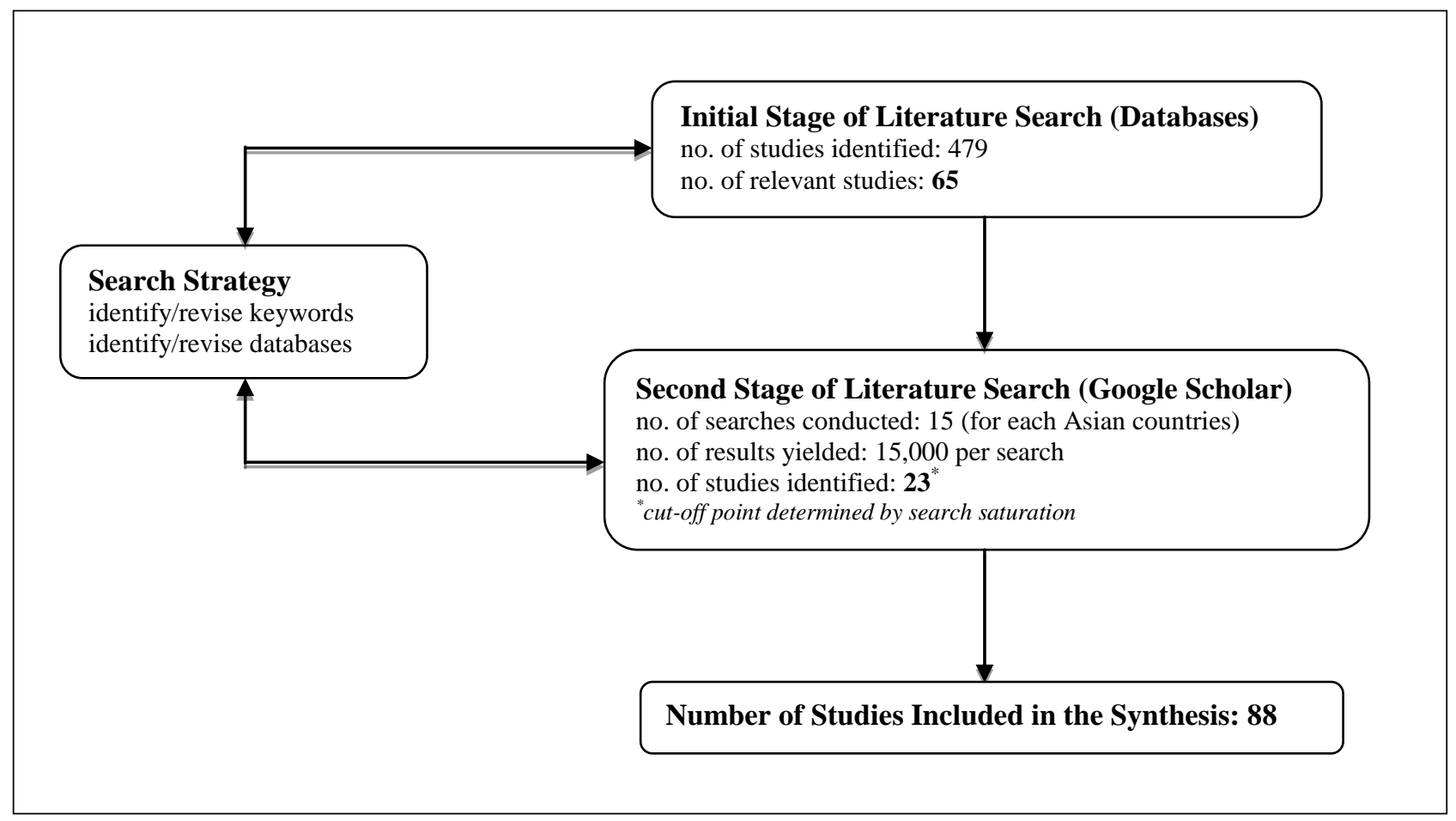

Word count: 10,610 